\title{
Could anti-mullerian hormone be a useful predictor of the success of laparoscopic ovarian drilling?
}

\begin{abstract}
Aim: to assess the correlation between pre-ovarian drilling patients' demographic data and hormonal profile and subsequent spontaneous ovulation and conception following the procedure.

Methods: Prospective observational study including 145 primary infertility, clomiphene resistant patients with polycystic ovary syndrome, undergoing laparoscopic ovarian drilling (LOD). The selected patients were directed to have LOD. Ovulation was diagnosed by serial follow up ultrasonography in the subsequent cycles confirmed by day 21 progesterone. Antimullerian hormone (AMH), lutenizing hormone ( $\mathrm{LH})$ and prolactin assays were done before and 3 months after the procedure. Receiver operator curve was used to correlate between demographic and hormonal data and spontaneous ovulation following the procedure.

Results: There was a significant reduction of AMH, LH and prolactin after LOD in both groups $(\mathrm{P}<0.001)$ but the decrease in post-LOD AMH and prolactin is less pronounced in the non-ovulatory group which is significantly higher than in the ovulatory group $(\mathrm{P}<0.001)$. The logistic regression analysis revealed that pre-LOD AMH is highly predictive of nonovulation at a cut off value of $8.8 \mathrm{ng} / \mathrm{ml}$ with sensitivity of $77 \%$ and specificity of $72 \%$ $(\mathrm{P}<0.001)$. Other demographic and hormonal data was not significant.
\end{abstract}

Conclusion: AMH could be used as a good predictor of ovarian response to LOD. Larger trials are warranted to confirm or refute this finding.

Keywords: polycystic ovary syndrome, antimullerian hormone, laparoscopic ovarian drilling
Volume 3 Issue 2 - 2015

\author{
Mohamed Abo-Elnasr ${ }^{1,2}$ \\ 'Department of Obstetrics and Gynecology, Menoufia \\ University, Egypt \\ ${ }^{2}$ Department of Obstetrics and Gynecology, Taibah University, \\ Saudi Arabia

\begin{abstract}
Correspondence: Mohamed Abo-Elnasr, Department of Obstetrics and Gynecology, Faculty of Medicine, Menoufia University, Menoufia, Egypt, Tel 201096999838,
\end{abstract} \\ Email:mohamed_aboelnasr6I@yahoo.com
}

Received: October 13,2015 | Published: November 12, 2015
Abbreviations: PCOS, polycystic ovary syndrome; LOD, laparoscopic ovarian drilling; AMH, anti mullerian hormone; LH, lutenizing hormone; ESHRE, european society of human reproduction and embryology; ASRM, American society for reproductive medicine; ROC, receiver-operating characteristic; BMI, body mass index

\section{Introduction}

Polycystic ovary syndrome (PCOS) is one of the most common endocrine disorders and the leading cause of infertility in women of reproductive age. ${ }^{1}$ The first line of infertility treatment is clomiphene citrate, the second line includes gonadotrophins or laparoscopic ovarian drilling (LOD) and the third is IVF. ${ }^{2}$ The mechanism of action of LOD is not fully understood and therefore it is not exactly clear why some PCOS patients do not respond to this treatment. ${ }^{3}$ The aim of this study was to assess the correlation between patients' demographic data and hormonal profile and poor ovarian response to LOD.

\section{Materials and methods}

A prospective Observational study was designed taking 145 primary infertility, clomiphene resistant patients, admitted to the Department of Obstetrics and Gynecology, Menoufia University hospital, Menoufia, Egypt in the period between October 2008 to March 2011.

The respective approvals of the review board and the ethics committee of the Menoufia Faculty of medicine were obtained before commencing the study. The study protocol and its benefits and complications were explained to all participants, and all recruited patients completed and signed the 'informed consent' form. The assumed total sample size of the study was actually calculated according to a proposed type I error of 5\% with an expected difference between rates of spontaneous ovulation of 50-90\%. Type II error was proposed to be $20 \%(\beta=20 \%)$ hence the power was set at $(1-\beta$, $80 \%$ ). Accordingly, 120 patients were needed after adding a $10 \%$ for possible drop out of cases.

Included patients with PCOS were diagnosed according to the revised European Society of Human Reproduction and Embryology (ESHRE) and American Society for Reproductive Medicine (ASRM) criteria of 2004 which were based on the Rotterdam criteria. ${ }^{4}$

Clomiphene citrate resistance was defined as the absence of developing follicles after ovarian stimulation with $150 \mathrm{mg}$ clomiphene citrate/day given for five days beginning with the 2nd day of the menstrual cycle. Patients were stimulated with clomiphene for a minimum of three and a maximum of six cycles. ${ }^{5}$ A normal semen analysis, normal uterine cavity and bilateral tubal patency were the criteria of inclusion.

Patients with FSH $>15 \mathrm{mIU} / \mathrm{ml}$, medical disorders such as Diabetes Mellitus and hypertension, contraindications for laparoscopy, Endocrine disorders: hyperprolactinaemia (prolactin $\geq 22 \mathrm{ng} / \mathrm{dl}$ ), Thyroid disorders, Cushing's syndrome and Acromegaly, husband semen abnormalities and patients having organic pelvic disease (endometriosis, leiomyoma, PID, endometrioma or ovarian cyst) upon laparoscopy were excluded from the study. Patients baseline blood samples were obtained before laparoscopic ovarian drilling (2-3 days after the commencement of spontaneous or progesterone induced menstrual bleeding) to assess serum levels of AMH, LH and prolactin. The second blood sample was obtained in the early follicular phase (days 2-3) of the menstrual cycle after 3 months of the operation. 
AMH assay was done using a commercial ELISA kits (Immunotech, Beckman-coulter UK Ltd, High Wycombe Buckinghamshire UK), according to the manufacturer, the sensitivity of the assay is $0.24 \mathrm{ng} /$ $\mathrm{mL}$. LH assay was performed using automated microparticles enzyme immunoassay (Abbott Axsyem analyzer, Abbott Diagnostics). Midluteal serum progesterone was measured via Radioimmunassay (Immunotech, Westbrook, ME, USA) and prolactin (Immunotech, Westbrook, ME, USA).

Pelvic sonography (Acuson 128XP 10, computed sonography system, Mountain View, California, USA) was carried out on day 12-16 for folliculometry before and after the operation. Ovulation is defined as the presence of at least one dominant follicle measuring $\geq 18 \mathrm{~mm}$. Laparoscopic ovarian drilling (LOD) was performed using three-puncture technique. The laparoscope was introduced through a subumblical incision. After assessment of the pelvic structures and tubal patency, an insulated needle connected to a unipolar electrocautery with four to six cautery points $3-4 \mathrm{~mm}$ in diameter was created in each ovary with a current of $4 \mathrm{~mA}$ applied through the laparoscopic insulated needle.

Ovulation was diagnosed by serial follow up ultrasonography in the subsequent cycle confirmed by day 21 progesterone. If no menses occurred within 6 weeks, withdrawal bleeding was done and the patients were followed up for 3 months and considered as non-ovulatory. Patients were categorized into two groups, ovulatory $(n=98)$ and non-ovulatory $(n=47)$ groups. Patients in both groups were followed via regular visits to the outpatient clinic every 2-4 weeks to record the pregnancy rate.

\section{Outcome measures}

1. The primary outcome was to assess the utility of patients' demographic criteria and hormonal profile for the prediction of poor ovarian response to LOD.

2. Secondary outcome was to record the pregnancy rate in the ovulatory group during the subsequent 15 months.

\section{Statistical analysis}

Statistical analysis was performed using Statistical Package for the Social Sciences Version 16 (IBM Corp., Armonk, NY, USA). Quantitative data are expressed as means and standard deviations. Chisquared test and t-test were used to compare the two groups. $\mathrm{p} \leq 0.05$ was considered to indicate significance and $p \leq 0.001$ was considered to indicate strong significance. Receiver-operating characteristic (ROC) curve analysis was used to evaluate the prognostic value of demographic and hormonal data.

\section{Results}

Table 1 displays the patients' demographic data. No significant difference between the ovulatory and non-ovulatory groups regarding age, body mass index (BMI) and duration of infertility. Table 2 reveals the hormonal profile before and three months after LOD. There is a significant reduction of $\mathrm{AMH}, \mathrm{LH}$ and prolactin after LOD in both groups $(\mathrm{P}<0.001)$. Post-LOD AMH and prolactin are higher in the non-ovulatory group than in the ovulatory group $(\mathrm{P}<0.001)$.

Table 3 shows the logistic regression analysis of patients characteristics and hormonal profile among the participants (total no 145). Pre-LOD AMH is highly predictive of non-ovulation at a cut off value of $8.8 \mathrm{ng} / \mathrm{ml}$ with sensitivity of $77 \%$ and specificity of $72 \%$
$(\mathrm{P}<0.001)$. Table 4 shows the pregnancy rate in the ovulatory group over 15 months (82/98). Pregnancy rate within the first 6 months was $60 / 82(74.4 \%)$ with 22 women $(25.6 \%)$ conceived in the subsequent 6 months.

Table I Patients' demographic data

\begin{tabular}{lllll}
\hline & $\begin{array}{l}\text { Ovulatory } \\
\text { group } \\
(\mathbf{n = 9 8 )}\end{array}$ & $\begin{array}{l}\text { Non- } \\
\text { ovulatory } \\
\text { group } \\
(\mathbf{n = 4 7 )}\end{array}$ & $\begin{array}{l}\text { Student } \\
\text { t-test }\end{array}$ & P-value \\
\hline Age (in years) & $29.7 \pm 1.5$ & $29.8 \pm 1.4$ & 0.38 & $>0.05$ \\
$\begin{array}{l}\text { Body Mass } \\
\text { Index }\end{array}$ & $27.9 \pm 2.1$ & $28.4 \pm 1.8$ & 1.4 & $>0.05$ \\
$\begin{array}{l}\text { Duration of } \\
\text { Infertility (in } \\
\text { years) }\end{array}$ & $5.4 \pm 0.7$ & $5.2 \pm 0.5$ & 1.75 & $>0.05$ \\
\hline
\end{tabular}

Table 2 Hormonal profile before and after LOD

\begin{tabular}{lllll}
\hline & $\begin{array}{l}\text { Ovulatory } \\
\text { group }(\mathbf{n = 9 8})\end{array}$ & $\begin{array}{l}\text { Non-ovulatory } \\
\text { group }(\mathbf{n = 4 7})\end{array}$ & $\begin{array}{l}\text { Student } \\
\text { t-test }\end{array}$ & P-value \\
\hline AMH & $14.2 \pm 4.7$ & $14.6 \pm 4.6$ & 0.48 & $>0.05$ \\
Before LOD & $8.6 \pm 3.2$ & $12.2 \pm 3.2$ & 6.43 & $<0.001$ \\
After LOD & $\mathrm{P}<0.001$ & $\mathrm{P}<0.05$ & & \\
LH & $21.1 \pm 4.8$ & $21.7 \pm 4.5$ & 0.72 & $>0.05$ \\
Before LOD & $15.3 \pm 3.4$ & $15.8 \pm 3.2$ & 0.84 & $>0.05$ \\
After LOD & $\mathrm{P}<0.001$ & $\mathrm{P}<0.001$ & & \\
& & & & \\
Prolactin & & $\mathrm{P}$ & & \\
Before LOD & $28.2 \pm 5.1$ & $28.8 \pm 4.9$ & 0.67 & $>0.05$ \\
After LOD & $8.5 \pm 3.7$ & $15.2 \pm 6.3$ & 8.04 & \\
& $\mathrm{P}<0.001$ & $\mathrm{P}<0.001$ & & \\
& & & & \\
\hline
\end{tabular}

$\mathrm{AMH}$, antimullerian hormone; $\mathrm{LH}$, leutinizing hormone

Table 3 The logistic regression analysis of patients' characteristics and hormonal profile among the participants (Total no 145)

\begin{tabular}{llllll}
\hline & AUC & Sensitivity & Specificity & $\begin{array}{l}\text { Cut-off } \\
\text { value }\end{array}$ & P-value \\
\hline Age & 0.586 & $63 \%$ & $69 \%$ & - & $>0.05$ \\
BMI & 0.658 & $55 \%$ & $61 \%$ & - & $>0.05$ \\
$\begin{array}{l}\text { Infertility } \\
\text { Duration }\end{array}$ & 0.642 & $64 \%$ & $52 \%$ & - & $>0.05$ \\
AMH & 0.714 & $77 \%$ & $72 \%$ & $8.8 \mathrm{ng} / \mathrm{ml}$ & $<0.001$ \\
LH & 0.66 & $61 \%$ & $69 \%$ & - & $>0.05$ \\
Prolactin & 0.626 & $58 \%$ & $62 \%$ & - & $>0.05$ \\
\hline
\end{tabular}

$\mathrm{BMI}$, body mass index; $\mathrm{AMH}$, antimullerian hormone; $\mathrm{LH}$, leutinizing hormone 
Table 4 Pregnancy rate $(n=82)$ in the ovulatory group over 15 months $(n=98)$

\begin{tabular}{llll}
\hline Category & $\begin{array}{l}\text { Pregnancy rate } \\
\text { after } 6 \text { months } \\
(\mathbf{n = 6 0 )}\end{array}$ & $\begin{array}{l}\text { Pregnancy rate } \\
\text { after 12 months } \\
(\mathbf{n = 2 2})\end{array}$ \\
\hline Age & $<25$ years & 42 & 16 \\
& $\geq 25$ years & 18 & 6 \\
BMI & $<25$ & 52 & 18 \\
Infertility & $\geq 25$ & 8 & 4 \\
duration & $\geq 5$ years & 54 & 20 \\
AMH & $<8.8$ & 56 & 2 \\
& $\geq 8.8$ & 4 & 21 \\
LH & $<10$ & 19 & 1 \\
& $\geq 10$ & 41 & 10 \\
Prolactin & $<10$ & 50 & 12 \\
& $\geq 10$ & 10 & 17 \\
\hline
\end{tabular}

$\mathrm{BMI}$, body mass index; $\mathrm{AMH}$, antimullerian hormone; $\mathrm{LH}$, leutinizing hormone

\section{Discussion}

In this series, 47 patients out of 145 were anovulatory (32.4\%) with ovulation reported in 98 patients $(77.6 \%)$. The reported ovulation rate after LOD varies between $50 \%$ and $90 \%$ in the literature. ${ }^{6}$ There is some disparity between hormonal improvement and ovulation rate following LOD. ${ }^{7}$

In this study, the amount of decrease in post-LOD AMH and prolactin is less pronounced in the non-ovulatory group since $\mathrm{AMH}$ and prolactin levels were significantly higher in the pre-LOD nonovulatory group than in the ovulatory group.

Gjonness et al. ${ }^{8}$ in their study on 17 women showed a transient hyperprolactinemia immediately after LOD, they believed that this phenomenon was due to operative stress. Hyperprolactinemia as a complication of operation, and/or anesthesia was previously described with the peak prolactin levels always occurring during surgery. Prolactin remained elevated in $62.5 \%$ when measured 6-10 weeks after operation. ${ }^{9-11}$

Another possible explanation of anovulation following LOD is that the amount of ovarian tissue destroyed during LOD is not sufficient to produce an effect in some patients. However, others believe that ovarian diathermy works by increasing the sensitivity of the ovaries to endogenous FSH, and that only a minimal amount of thermal injury is required. ${ }^{3}$

In this study, Pre-LOD AMH is highly predictive of non-ovulation at a cut off value of $8.8 \mathrm{ng} / \mathrm{ml}$ with sensitivity of $77 \%$ and specificity of $72 \%(\mathrm{P}<0.001)$. On the other hand, other demographic and hormonal data has no significant impact on the ovarian response to LOD.

A previous smaller study was conducted in UK to measure circulating $\mathrm{AMH}$ before laparoscopic ovarian diathermy (LOD) to evaluate its prognostic value for an ovulatory response and to investigate AMH changes after LOD to further explore the effects of LOD. This study included anovulatory women with PCOS undergoing LOD $(n=29)$ or receiving clomiphene citrate $(n=18)$. Plasma AMH concentrations were measured before and 1 week after treatment.
Further measurements of AMH were made at 3-and 6-month followup. AMH was found to be a useful predictor of no ovulation after LOD with area under the curve of $0.804(\mathrm{P}=0.025)$. Using a cut-off of $7.7 \mathrm{ng} / \mathrm{ml}$, AMH had a sensitivity of $78 \%$ and a specificity of $76 \%$ in the prediction of no ovulation after LOD. ${ }^{12}$

In our series $82(56.5 \%)$ patients get pregnant within 15 months in the ovulatory group. Pregnancy rate within the first 6 months was $60 / 82(74.4 \%)$ and 22 women (25.6\%) conceived in the subsequent 6 months. Pregnancy rate was higher in women younger than 25 years, with BMI less than 25 and infertility duration less than 5 years.

Many authors have reported high ovulation (about 80\%) and pregnancy (about 60\%) rates following LOD. ${ }^{13-16}$ Duleba et al. ${ }^{17}$ reported that lean PCOS women (BMI $<25 \mathrm{~kg} / \mathrm{m}^{2}$ ) achieved higher conception rates than overweight women $\left(\right.$ BMI $\left.>25 \mathrm{~kg} / \mathrm{m}^{2}\right)$ after laparoscopic wedge resection using a harmonic scalpel in 33 PCOS patients. ${ }^{17}$

In our series, ovulatory women with higher LH levels (>10IU/1) have a significantly higher chance of conception than those with lower LH levels which is consistent with previous studies. ${ }^{3,18}$ Failure of LOD in women with relatively high levels of AMH may be due to severity of the PCOS condition in these women. It is possible that the extent of follicle destruction by LOD in these women was not enough to reduce intra-ovarian $\mathrm{AMH}$ to a level consistent with resumption of ovulation. ${ }^{12}$ Future research should explore the use of dose adjusted LOD in relation to the serum levels of AMH and subsequent ovulation and pregnancy rates. From the results obtained in this clinical study, AMH could be used as a good predictor of ovarian response to LOD. Larger trials are warranted to confirm or refute this finding.

\section{Acknowledgments}

The author would like to acknowledge the contribution of the residents and nursing staff of the operating room and clinical pathology department of Menoufia university Hospital.

\section{Conflicts of interest}

The authors declare there is no conflict of interests.

\section{References}

1. Goldenberg N, Glueck C. Medical therapy in women with polycystic ovarian syndrome before and during pregnancy and lactation. Minerva Ginecol. 2008;60(1):63-75.

2. Thessaloniki ESHRE/ASRM-Sponsored PCOS Consensus Workshop Group. Revised 2003 consensus on diagnostic criteria and long- health risks related to polycystic ovary syndrome (PCOS). Hum Reprod. 2008;23(3):462-477.

3. Amer SA, Li TC, Ledger WL. Ovulation induction using laparoscopic ovarian drilling in women with polycystic ovarian syndrome: predictors of success. Hum Reprod. 2004;19(8):1719-1724.

4. Rotterdam ESHRE/ASRM-Sponsored PCOS Consensus Workshop Group. Revised 2003 consensus on diagnostic criteria and longterm health risks related to polycystic ovary syndrome. Fertil Steril. 2004;81(1):19-25.

5. Thessaloniki ESHRE/ASRM-Sponsored PCOS Consensus Workshop Group. Consensus on infertility treatment related to polycystic ovary syndrome. Hum Reprod. 2008;23(3):462-477.

6. Abdel Ghadir A, Khatim MS, Mowafi RS, et al. Ovarian electrocautery versus human menopausal gonadotropins and pure follicle stimulatin 
hormone therapy in the treatment of the patients with polycystic ovarian disease. Clin Endocrinol. 1990;33(5):585-592.

7. Balen AH, Jacobs HS. A prospective study comparing unilateral and bilateral laparoscopic ovarian diathermy in women with the polycystic ovary syndrome. Fertil Steril. 1994;62(5):921-925.

8. Gjonnaess H, Norman. Endocrine effects of ovarian electrocautery in patients with polycystic ovarian disease. $\mathrm{Br} J$ Obstet Gynaecol. 1987;94(8):779-783.

9. Adashi EY, Rebar RW, Ehara Y, et al. Impact of acute surgical stress on anterior pituitary function in female subjects. Am J Obstet Gynecol. 1980;138(6):609-614.

10. Soules MR, Sutton GP, Hammond CB, et al. Endocrine changes at operation under general anesthesia: Reproductive hormone flactuations in young women. Fertil Steril. 1980;33(4):364-371.

11. Parsanezhad ME, Alborzi S, Zolghadri J, et al. Hyperprolactinemia after laparoscopic ovarian drilling: An unknown phenomenon. Reprod Biol Endocrinol. 2005;3:31.

12. Amer SA, Li TC, Ledger WL. The value of measuring antiMullerian hormone in women with anovulatory polycystic ovary syndrome undergoing laparoscopic ovarian diathermy. Hum Reprod. 2009;24(11):2760-2766.
13. Felemban A, Tan SL, Tulandi T. Laparoscopic treatment of polycystic ovaries with insulated needle cautery: a reappraisal. Fertil Steril. 2000;73(2):266-269.

14. Amer SA, Gopalan V, Li TC, et al. Long term follow-up of patients with polycystic ovarian syndrome after laparoscopic ovarian drilling: clinical outcome. Hum Reprod. 2002;17(8):2035-2042.

15. Mohiuddin S, Bessellink D, Farquhar C. Long-term follow up of women with laparoscopic ovarian diathermy for women with clomipheneresistant polycystic ovarian syndrome. Aust $N Z$ J Obstet Gynaecol. 2007;47(6):508-511.

16. Flyckt RL, Goldberg JM. Laparoscopic ovarian drilling for clomipheneresistant polycystic ovary syndrome. Semin Reprod Med.2011;29(2):138146.

17. Duleba AJ, Banaszewska B, Spaczynski RZ, et al. Success of laparoscopic ovarian wedge resection is related to obesity, lipid profile, and insulin levels. Fertil Steril. 2003;79(4):1008-1014.

18. Li TC, Saravelos H, Chow MS, et al. Factors affecting the outcome of laparoscopic ovarian drilling for polycystic ovarian syndrome in women with anovulatory infertility. BJOG. 1998;105(3):338-344. 